\title{
Miocene abyssochrysoid gastropod Provanna from Japanese seep and whale-fall sites
}

Kazutaka Amano and Crispin T.S. Little

Acta Palaeontologica Polonica 59 (1), 2014: 163-172 doi: http://dx.doi.org/10.4202/app.2012.0002

We describe three Miocene species of Provanna from Japan, two new and one in open nomenclature, that represent the only known fossil examples from whale-falls and a considerable increase in the Miocene diversity of the genus. Provanna hirokoae sp. nov. comes from the latest Middle Miocene Kuroiwa seep site in central Honshu. The shells of this species are mostly recrystallized, but contain relict crossed lamellar microstructures. Provanna alexi sp. nov. is from the early Middle Miocene Shosanbetsu whale-fall site in northwestern Hokkaido, and has well preserved shells comprising an outer simple prismatic layer and an inner crossed lamellar layer. The two Provanna specimens from the Middle Miocene Rekifune whale-fall site, in eastern Hokkaido, are preserved as external moulds only, so are left in open nomenclature. Based on current knowledge, the presence of an outer prismatic layer and an underlying crossed lamellar layer seems to be a common feature in the shells of Provanna, as well as in other genera belonging to the family Provannidae and the superfamily Abyssochrysoidea. Although the oldest occurrence of Provanna was in the Late Cretaceous, the genus did not spread geographically and ecologically until the Miocene (with four, or possibly five species), a date concordant with some molecular estimates. However, this could be an artefact of the fossil record because the known pre-Miocene seep and whale-falls are more geographically restricted than those from the Miocene.

Key words: Mollusca, Gastropoda, Provanna, seep, whale-fall, Miocene, Japan.

Kazutaka Amano [amano@juen.ac.jp], Department of Geoscience, Joetsu University of Education, 1 Yamayashiki, Joetsu 943-8512, Japan; Crispin T.S. Little [earcts1@leeds.ac.uk], School of Earth and Environment, University of Leeds, Leeds LS2 9JT, United Kingdom.

This is an open-access article distributed under the terms of the Creative Commons 
Attribution License (for details please see creativecommons.org), which permits unrestricted use, distribution, and reproduction in any medium, provided the original author and source are credited.

Fof Full text $(712.7 \mathrm{kB})$ 